\title{
Childhood traffic-related air pollution and adverse changes in subclinical atherosclerosis measures from childhood to adulthood
}

Shohreh F. Farzan ${ }^{1 *}$ (D), Rima Habre1, Phoebe Danza', Frederick Lurmann², W. James Gauderman', Edward Avol', Theresa Bastain ${ }^{1}$, Howard N. Hodis ${ }^{1,3,4}$ and Carrie Breton ${ }^{1}$

\begin{abstract}
Background: Chronic exposure to air pollutants is associated with increased risk of cardiovascular disease (CVD) among adults. However, little is known about how air pollution may affect the development of subclinical atherosclerosis in younger populations. Carotid artery intima-media thickness (CIMT) is a measure of subclinical atherosclerosis that provides insight into early CVD pathogenesis.
\end{abstract}

Methods: In a pilot study of 70 participants from the Southern California Children's Health Study, we investigated CIMT progression from childhood to adulthood. Using carotid artery ultrasound images obtained at age 10 and follow-up images at age 21-22, we examined associations between childhood ambient and traffic-related air pollutants with changes in CIMT over time and attained adult CIMT using linear mixed-effects models adjusted for potential confounders.

Average residential childhood exposures (i.e., birth to time of measurement at 10-11 years) were assigned for regional, ambient pollutants (ozone, nitrogen dioxide, particulate matter, interpolated from regulatory air monitoring data) and traffic-related nitrogen oxides $\left(\mathrm{NO}_{x}\right.$ ) by road class (modeled using the CALINE4 line source dispersion model). Traffic density was calculated within a 300-m residential buffer.

Results: For each 1 standard deviation (SD) increase in childhood traffic-related total $\mathrm{NO}_{\mathrm{x}}$ exposure, we observed greater yearly rate of change in CIMT from childhood to adulthood ( $\beta: 2.17 \mu \mathrm{m} / \mathrm{yr}$, 95\% Cl: 0.78-3.56). Increases in annual rate of CIMT change from childhood to adulthood also were observed with freeway $\mathrm{NO}_{x}$ exposure ( $\beta$ : $2.24 \mu \mathrm{m} / \mathrm{yr}, 95 \% \mathrm{Cl}: 0.84-3.63)$ and traffic density (B: $2.11 \mu \mathrm{m} / \mathrm{yr}, 95 \% \mathrm{Cl}: 0.79-3.43)$. Traffic exposures were also related to increases in attained CIMT in early adulthood. No associations of CIMT change or attained level were observed with ambient pollutants.

* Correspondence: sffarzan@uscedu

'Department of Preventive Medicine, Keck School of Medicine of University of Southern California, 2001 N. Soto Street, Los Angeles, CA 90089, USA

Full list of author information is available at the end of the article

(c) The Author(s). 2021 Open Access This article is licensed under a Creative Commons Attribution 4.0 International License, which permits use, sharing, adaptation, distribution and reproduction in any medium or format, as long as you give appropriate credit to the original author(s) and the source, provide a link to the Creative Commons licence, and indicate if changes were made. The images or other third party material in this article are included in the article's Creative Commons licence, unless indicated otherwise in a credit line to the material. If material is not included in the article's Creative Commons licence and your intended use is not permitted by statutory regulation or exceeds the permitted use, you will need to obtain permission directly from the copyright holder. To view a copy of this licence, visit http://creativecommons.org/licenses/by/4.0/. The Creative Commons Public Domain Dedication waiver (http://creativecommons.org/publicdomain/zero/1.0/) applies to the data made available in this article, unless otherwise stated in a credit line to the data. 
(Continued from previous page)

Conclusions: Overall, we observed adverse changes in CIMT over time in relation to childhood traffic-related $\mathrm{NO}_{x}$ exposure and traffic density in our study population. While these results must be cautiously interpreted given the limited sample size, the observed associations of traffic measures with CIMT suggest a need for future studies to more fully explore this relationship.

Keywords: Carotid intima media thickness, Air pollution, Traffic, Atherosclerosis, Childhood

\section{Background}

Cardiovascular disease (CVD) remains a growing public health issue across the globe, and CVD incidence is predicted to increase steadily over the coming decades $[1,2]$. Despite more effective treatments and greater awareness of risk factors, CVD continues to be the leading cause of death worldwide, accounting for nearly a third ( $\sim 18$ million) of all deaths each year [3]. More than $80 \%$ of CVD has been attributed to modifiable factors, including environmental exposures [4-10]. Given the high incidence of CVD, even small increases in risk due to environmental factors may translate to a considerable increase in the number of individuals who develop CVD.

Air pollution has emerged as a key contributor to many chronic diseases, including CVD, and a large body of evidence supports both the acute and chronic cardiovascular effects of air pollution exposure [8, 9, 11-19]. Epidemiological and experimental studies have linked air pollutant exposures to multiple risk factors for CVD [20-27], including carotid artery intima media thickness (CIMT), a widely used measure of subclinical atherosclerosis [28, 29], and carotid arterial stiffness (CAS), a measure of endothelial function indicative of vascular health [30]. While the majority of studies have focused on the role of ambient pollutants, proximity to traffic also has been associated with atherosclerosis, as measured by CIMT and/or coronary artery calcification, in several studies among adults [31-34]. Further, two studies of long-term exposure to fine particulate matter $\left(\mathrm{PM}_{2.5}\right)$ and traffic-related pollutants found associations with accelerated progression of atherosclerosis, as measured by increases in CIMT over time [32, 35]. Together, these studies provide a strong body of evidence supporting a role for ambient and traffic-related air pollutants in the development of CVD by promoting atherosclerosis, the key underlying pathological process that leads to clinical cardiovascular events.

Despite the relatively strong evidence linking air pollution and CVD in adults, very little is known about the origins of CVD in early stages during childhood and adolescence, particularly in relation to air pollution. A limited number of studies suggest that air pollution exposure may be related to adverse cardiovascular changes in children and young adults [21,36-40]. A number of studies have observed that prenatal and early air pollution exposures are related to adverse changes in childhood cardiovascular risk factors, such as blood pressure (BP) and body mass index (BMI) [41-46]. In studies of college students, prenatal exposure to fine particulate matter $\left(\mathrm{PM}_{2.5}\right)$ has been associated with increased CAS, while childhood exposure to ozone has been associated with greater CIMT in early adulthood $[21,22]$. While changes in childhood cardiovascular risk factors have been associated with increases in CIMT in later life [47-50], to our knowledge, no studies have examined changes in subclinical atherosclerosis over time in younger populations, particularly at the transition from childhood to adulthood, nor have others examined the potential role of air pollutants in early atherosclerosis progression during this critical life stage.

The Southern California Children's Health Study (CHS) is one of the largest and most comprehensive investigations of the long-term effects of air pollution on children's health [51-54]. In a study of $70 \mathrm{CHS}$ participants, we measured CIMT in both childhood and adulthood and examined longitudinal changes in this measure of subclinical atherosclerosis over this critical development time. Leveraging the extensive and wellcharacterized exposure data available in the CHS, we assessed the impact of both ambient and traffic-related air pollutants on patterns of CIMT change over time and on attained CIMT level in adulthood.

\section{Methods}

The Southern California Children's Health Study

The Children's Health Study (CHS) began in 1993 and since its initiation, five discrete CHS cohorts have been established to evaluate the health effects of air pollution in school children who were followed prospectively from 6 until 18 years of age. The CHS is one of the largest and most comprehensive investigations of the long-term effects of air pollution on the respiratory health of children, and portions of the CHS have been followed for over 20 years [51, 52, 55, 56]. As part of the NIH Environmental Influences on Child Health Outcomes (ECHO) consortium (UH3OD023287), we are actively following participants from the fifth CHS cohort ("Cohort E"), in which approximately five thousand children from kindergarten and first grade in 2002-2003 were enrolled. These children were recruited from 13 communities, 
representing a range of levels and mixtures of regional ambient air pollutants, including particulate matter (PM), nitrogen dioxide $\left(\mathrm{NO}_{2}\right)$ and ozone $\left(\mathrm{O}_{3}\right)[55,56]$. Existing childhood data (from age 5 through 18) collected on CHS participants include parental sociodemographic factors, annual health questionnaires, annual measurements of height and weight to obtain validated measures of BMI, as well as multiple years of pulmonary function testing and exhaled nitric oxide measurements. Of those enrolled in CHS Cohort E, a subset children from 8 CHS communities were selected for a carotid artery ultrasound assessment during their annual visit at approximately 10-11 years of age (school year of 20072008) [36]. Children were selected to receive a CIMT measurement in childhood based on parental report that the child lived in a non-smoking household and had lived in the same residence from birth until time of CIMT measurement in one of 8 selected CHS communities. Children meeting these criteria in were invited to participate and were measured upon receipt of parental consent, resulting in 737 children with CIMT measurement. For the purpose of this study, we contacted only participants from cohort $\mathrm{E}$ who had a childhood carotid artery ultrasound examination to participate in this follow-up study [36]. All participants provided written informed consent prior to enrollment. All protocols and study materials were approved by the University of Southern California's Institutional Review Board.

\section{In-person assessment of CHS participants in early adulthood}

Participants were re-contacted by phone and/or email approximately 11 years after their initial carotid ultrasound and invited to participate in an in-person followup visit at our ECHO study clinic. At the time of this study, approximately 530 Cohort E CHS participants of the original 737 children with CIMT measurements had recently updated contact information (e.g. phone number and/or email updated within 5 years), and records indicated that they lived in CA (for exposure assessment purposes, i.e. CALINE4 traffic estimates) within driving distance $(\sim 2.5 \mathrm{~h})$ of our study clinic. From those 530 individuals, a convenience sample of the first 70 participants who to agree to participate in an in-person assessment were enrolled and provided written informed consent prior to assessment. While participants were not randomly selected for this pilot study, key characteristics of these 70 individuals, including community of origin, race/ethnicity and sex, are similar to the distributions observed in the original subset of 737 individuals with carotid ultrasound in childhood. Participants were asked to complete a number of questionnaires developed as part of the ECHO program that included questions about demographics, current lifestyle and habits, such as personal cigarette smoking and family health history including cardiovascular disease such as hyperlipidemia, hypertension, stroke and coronary artery disease. Trained study coordinators conducted duplicate measurements of weight and standing height, using standard protocols [57]. A third measurement of weight and/or height was taken if the first two measurements differed by more than $0.05 \mathrm{~kg}$ or $1 \mathrm{~cm}$, respectively. Height and weight measures were used to calculate body mass index (BMI; $\mathrm{kg} / \mathrm{m}^{2}$ ), which in turn was used to categorize study subjects (underweight $/$ normal $<25 \mathrm{~kg} / \mathrm{m}^{2}$, overweight ( $\geq 25$ to $29.99 \mathrm{~kg} / \mathrm{m}^{2}$ ), obese, $\geq 30 \mathrm{~kg} / \mathrm{m}^{2}$ ), according to CDC guidelines [58]. After $5 \mathrm{~min}$ of rest, systolic and diastolic blood pressure were measured in triplicate with 1-min rest intervals between measurements using a GE Carescape Dinamap V100. Blood pressure measurements were averaged for analyses.

\section{Carotid artery ultrasound imaging and measures of atherosclerosis progression}

Carotid artery ultrasound images were obtained from young adult participants during the in-person clinic visit (mean age at assessment $=21.9$ (SD 0.4) years). Imaging was conducted at the USC Atherosclerosis Research Unit (ARU) by the same technician who conducted all childhood ultrasound scans at age 10-11. Acquisition of ultrasound images and subclinical carotid artery atherosclerosis was conducted with standardized procedures and technology specifically developed for longitudinal measurements of atherosclerosis at the ARU [59-62]. In brief, high resolution B-mode ultrasound carotid artery images were acquired using a Siemens Acuson CV70 (Mountain View, CA) ultrasound imaging system using a linear array 7.5 MHz transducer [61]. Single lead electrocardiogram (ECG) and ultrasound images were simultaneously recorded to ensure that vascular measurements occurred at the same time in cardiac cycle. The right carotid artery was imaged where the jugular vein and carotid artery were imaged transversely and then longitudinally with the former vessel stacked above the latter providing internal anatomical landmarks used for reproducing ultrasound transducer angulation and replicate image acquisition. Simultaneously visualizing the previously acquired ultrasound image from which CIMT was measured during childhood (10-11 years of age), internal anatomical landmarks were used to acquire the replicate ultrasound image for measurement of adult CIMT (20-21 years of age). Ultrasound image processors were blinded to all exposure information to avoid bias.

Arterial dimensions including far wall CIMT were measured at sub-pixel resolution using automated computerized edge detection software (Patents 2005, 2006, 2011) $[59,60]$. CIMT was determined as the average of 
70 to 100 measurements between the intima-lumen and media-adventitia interfaces along a 1-cm length just proximal to the carotid artery bulb at the same point of the cardiac cycle. This method standardizes the location and the distance over which CIMT is measured, ensuring comparability within and across participants [59, 60]. CIMT is a widely used measure of subclinical atherosclerosis that has been associated with risk of CVD events [28, 29]. Our CIMT methodology has been correlated with change in coronary artery disease assessed by quantitative coronary angiography and is predictive of clinical coronary events $[28,63]$.

\section{Calibration of ultrasound imagers and quality assurance} Childhood and adult ultrasound images were obtained using different ultrasound imaging equipment. Childhood ultrasound images at age 10-11 were obtained on a GE LOGIQ imager [36], which has limitations for long-term future use (i.e., outdated equipment with limited image storage capacity), while adult ultrasound images were obtained using current imaging technology (Siemens Acuson CV70) by the same ultrasound technician. To ensure comparability between childhood and adult images, duplicate ultrasound images were obtained from 29 adult participants using both the GE and Siemens ultrasound imaging systems. Reliability of outcome measurements performed across the ultrasound imaging systems was explored by calculating intra-class correlations between all measures that were performed in duplicate on both the GE and Siemens systems. Reliability of measurements between image analysts was also calculated for a subset of images.

\section{Exposure assessment}

Residential histories were compiled and geocoded at the monthly level for all participants, starting from preconception through the date of the adult follow-up assessment. Timelines integrate several information sources (e.g. birth certificates, questionnaires, etc.) and explicitly quantify spatial and temporal uncertainty in location ascertainment. These timelines form the basis of all air pollution exposure assessments. For the purposes of this study, we focused on childhood exposures spanning the period from birth until the time of first ultrasound assessment in childhood ( age 10-11 years). Ambient exposures to regional $\mathrm{PM}_{10}, \mathrm{PM}_{2.5}, \mathrm{O}_{3}$ and $\mathrm{NO}_{2}$ were assigned at a monthly level (averaged from daily with $75 \%$ completeness criterion) using inversedistance squared (IDW2) spatial interpolation based on the US Environmental Protection Agency's regulatory air monitoring network data and CHS measurements. Given the relatively high monitoring network density in southern California compared to other regions in the United States [64], this approach provides adequate prediction of regional, background exposures and mainly captures their temporal variability.

Traffic density within a 300-m buffer around the residence was calculated using annual average daily traffic (AADT) volumes. Annual changes were scaled to the 2002 Southern California air basin fleet NOx emissions. The roadway network data was retrieved for all road classes from the ESRI Streetmap Premium national database. Traffic density was calculated across 4 road classes defined by Feature Class Codes (FCC) (freeway (FCC1), highway (FCC2), major collector (FCC3), minor collector and arterials (FCC4)).

We used the California Line Source (CALINE4) dispersion model [65] to estimate residential monthly $\mathrm{NO}_{x}$ concentrations from nearby on-road vehicular traffic on freeways (defined as FCC1 + FCC2 roads), non-freeways (FCC3 + FCC4 roads) and their total (as the sum of the two categories). This model is well suited for estimating vehicle emissions concentrations downwind of roadways $[66,67]$ and near-road freeway concentrations [68-71]. CALINE $\mathrm{NO}_{\mathrm{x}}$ estimates by road class capture mainly spatial variability in emissions, traffic volume and roadway geometries as well as temporal variability in meteorology impacting dispersion of on-road vehicle emissions downwind.

\section{Statistical models}

We calculated descriptive statistics for all variables of interest, including demographic characteristics, exposure metrics and outcome measures. Differences in CIMT change between demographic variable categories were assessed by t-test or one-way ANOVA. Trends in CIMT over time were visualized using scatter plots to compare outcome measurements at age 10-11 to measurements at age 21-22. Spearman correlations between all ambient and traffic-related pollutants were calculated.

Using linear mixed effects models adjusted for covariates, we examined each of the ambient and trafficrelated air pollutant exposure variables with attained CIMT at the time of the adult ultrasound assessment, and the yearly change in CIMT from childhood to adulthood. Average childhood air pollutant exposures from birth to time of childhood CIMT measurement were determined by averaging monthly residential estimates of ambient and traffic-related pollutants. Yearly average change CIMT was determined by subtracting the child CIMT measurement value from the adult CIMT measurement value and dividing by total years between the two CIMT measurements. Effect estimates were scaled to a 1 standard deviation increase in the indicated exposure variable. Original study community (community at time of CHS enrollment in childhood) was determined to be a crucial study design variable, and both parental education (a proxy for socioeconomic status) 
and adult personal smoking behavior (categorized as never smokers, former smokers (no smoking within past 12 months), and recent smokers (any smoking within past 12 months)) were identified as important precision variables based on previous literature. Other potential confounders were then assessed by a one-by-one variable approach, and those that resulted in a pollutant-effect change larger than $10 \%$ were selected for inclusion in final models. BMI measures (i.e., adult BMI, child BMI and change in BMI over time) were each important (i.e. resulted in a pollutant-effect change larger than 10\%) for both attained and yearly change in CIMT over time, but only adult BMI was included in final models, given the high degree of correlation between adult and child BMI $(\mathrm{r}=0.71, p<0.0001)$, as well as between adult and change in BMI over time $(\mathrm{r}=0.75, p<0.0001)$. Final multivariate linear mixed models included personal smoking behavior, parental educational attainment and adult BMI, with community of enrollment included as a grouping variable. Family history of CVD and blood pressure (e.g. adult systolic blood pressure or change in systolic blood pressure over time) were considered as possible confounders, but neither were associated with CIMT in our study population, and therefore not included in final models. However, a sensitivity analysis including both family history of CVD and blood pressure as covariates was performed. Exploratory analyses stratified by sex were also performed. Statistical significance was determined at $p<0.05$ (two-sided). All analyses were performed using SAS 9.4 (SAS Institute, Inc., Cary, NC, USA).

\section{Results}

In our study population of $70 \mathrm{CHS}$ pilot participants, more than half of participants were female (58.6\%) (Table 1). The majority of participants self-identified as white $(62.9 \%)$ and more than half (54.3\%) identified as Hispanic. Sixty percent of participants had a normal adult body mass index (BMI), while about a third of participants were either overweight $(25.7 \%)$ or obese (10.0\%). Most participants reported never smoking (64.3\%), while $14.3 \%$ reported smoking in the past year. The majority of participants $(61.4 \%)$ reported having a family history of any cardiovascular health issues, such as high blood pressure, angina, heart disease or myocardial infarction. Overall, key characteristics of these 70 individuals, including community of origin, race/ethnicity and sex, are similar to the distributions observed in the original subset of 737 individuals with carotid ultrasound in childhood (Table S1). Ambient and traffic-related air pollutant exposures varied across participants (Table S2) and correlations between all ambient and traffic-related pollutant measurements were also examined (Table S3).
Table 1 Selected demographic characteristics of CHS participants $(N=70)$

\begin{tabular}{|c|c|}
\hline & $\begin{array}{l}\text { Mean (SD) or } \\
\mathrm{N}(\%)\end{array}$ \\
\hline Age at adult carotid ultrasound, years & $21.9(0.4)$ \\
\hline Age at child carotid ultrasound, years & $10.7(0.4)$ \\
\hline Change in age (time between ultrasounds), years & $11.1(0.3)$ \\
\hline \multicolumn{2}{|l|}{ Sex } \\
\hline Male & $29(41.4)$ \\
\hline Female & $41(58.6)$ \\
\hline \multicolumn{2}{|l|}{ Race } \\
\hline White & $44(62.8)$ \\
\hline More than one race & $14(20.0)$ \\
\hline Other $^{a}$ & $5(7.2)$ \\
\hline Unknown/not reported & $7(10.0)$ \\
\hline \multicolumn{2}{|l|}{ Ethnicity } \\
\hline Hispanic & $38(54.3)$ \\
\hline Non-Hispanic & $30(42.9)$ \\
\hline Unknown/not reported & $2(2.8)$ \\
\hline \multicolumn{2}{|l|}{ CHS recruitment community } \\
\hline Anaheim & $7(10.0)$ \\
\hline Glendora & $17(24.3)$ \\
\hline Long Beach & $1(1.4)$ \\
\hline Mira Loma & $5(7.1)$ \\
\hline Riverside & $7(10.0)$ \\
\hline San Dimas & $10(14.3)$ \\
\hline Santa Barbara & $10(14.3)$ \\
\hline Upland & $13(18.6)$ \\
\hline \multicolumn{2}{|l|}{ Parental Educational Attainment ${ }^{\text {b }}$} \\
\hline High school or less & $18(25.7)$ \\
\hline Some college or technical school & $21(30.0)$ \\
\hline Completed college or more & $31(44.3)$ \\
\hline Adult BMI $\left(\mathrm{kg} / \mathrm{m}^{2}\right)$ & $24.8(5.7)$ \\
\hline \multicolumn{2}{|l|}{ BMI category } \\
\hline Underweight $(<18.5)$ & $3(4.3)$ \\
\hline Normal $(18.5$ to $<25)$ & $42(60.0)$ \\
\hline Overweight (25 to < 30) & $18(25.7)$ \\
\hline Obese $(\geq 30)$ & $7(10.0)$ \\
\hline \multicolumn{2}{|l|}{ Smoking status at young adult follow-up } \\
\hline Never smoked & $45(64.3)$ \\
\hline Smoked but not in past 12 months & $15(21.4)$ \\
\hline Smoked in past 12 months & $10(14.3)$ \\
\hline \multicolumn{2}{|l|}{ Any family history of $\mathrm{CV}$ events ${ }^{c}$} \\
\hline No & 27 (38.6) \\
\hline Yes & $43(61.4)$ \\
\hline
\end{tabular}

${ }^{a}$ Other includes Asian, Pacific Islander, Alaska Native and American Indian ${ }^{\mathrm{b}}$ Parental education assessed prior to first CIMT measurement in childhood 'Events include hyperlipidemia (high cholesterol), hypertension (high blood pressure), stroke, coronary artery disease, and/or any other heart disease for any biological family members 
To ensure comparability of measurements between outcome measurements performed across the ultrasound imaging systems, intra-class correlations were calculated for measures that were performed in duplicate for 29 individuals on both the GE and Siemens systems. Mean CIMT values for each ultrasound imaging system were very highly correlated ( $\mathrm{ICC}=0.993$, range $0.985-0.996)$, indicating the comparability across machines and our ability to reliably compare CIMT from previously obtained images to current images (Table S4 and Figure S1). Reliability of measurements between image analysts was also calculated for a subset of images. The ICC for mean CIMT between image processors was very high $(\mathrm{ICC}=0.9998)$, indicating that our image acquisition, processing and measurement methods produce highly reproducible and comparable estimates including between ultrasound imaging systems.

CIMT increased by $20.9 \mu \mathrm{m}$ (SD: 65.9) (Table S5) on average between the age 10-11 years and 21-22 years measurements (Fig. 1), with an average yearly change in CIMT of $1.88 \mu \mathrm{m}$ (SD: 5.9 ) over the follow-up period. Mean attained CIMT at age 21-22 among our 70 participants was similar (580.2 $\mu \mathrm{m}, \mathrm{SD}: 70.9)$ (Table S5) to that of a Los Angeles university student population $(603.4 \mu \mathrm{m}, \mathrm{SD}: 54.5)$ and within range of normal values previously observed for this age group [72].

We also explored yearly rate of CIMT change over the follow-up period by various participant characteristics. We did not observe statistically significant differences in CIMT change by sex, race, ethnicity, smoking or blood pressure (Table 2). However, we observed differences in CIMT among BMI categories, such that greater yearly increases in CIMT were observed among individuals who were obese in childhood and/or obese in adulthood, as compared to other BMI categories (Table 2). We also observed that individuals with a family history of CVD appeared to have a greater yearly increase in CIMT $(2.52 \mu \mathrm{m} / \mathrm{yr}, \quad$ SD: $6.79, N=43)$ versus no history $(0.85 \mu \mathrm{m} / \mathrm{yr}, \quad$ SD: $3.87, N=27)$ over the follow-up period, but these differences were not statistically significant.

We observed larger increases over time in CIMT with increased childhood exposure to traffic.

For example, greater yearly changes in CIMT between age 10-11 and age 21-22 were associated with exposure to traffic-related total $\mathrm{NO}_{\mathrm{x}}$, such that a $1 \mathrm{SD}$ increase in childhood total $\mathrm{NO}_{x}$ was associated with an average yearly increase of $2.17 \mu \mathrm{m}$ (95\% CI: $0.78,3.56, p=0.003)$ in CIMT over the follow-up period (Table 3 and Figure S2). Similarly, a $1 \mathrm{SD}$ increase in childhood trafficrelated freeway $\mathrm{NO}_{x}$ exposure was associated with an average yearly increase of $2.24 \mu \mathrm{m}$ (95\% CI: $0.84,3.63$, $p=0.002$ ) in CIMT over the follow-up period (Table 3). Traffic density was related to statistically significant increases in CIMT over the follow-up, such that a $1 \mathrm{SD}$ increase in traffic density was associated with a mean yearly increase of $2.11 \mu \mathrm{m}$ (95\% CI: $0.79,3.43, p=0.002$ ) in CIMT. Childhood exposures to ambient pollutants

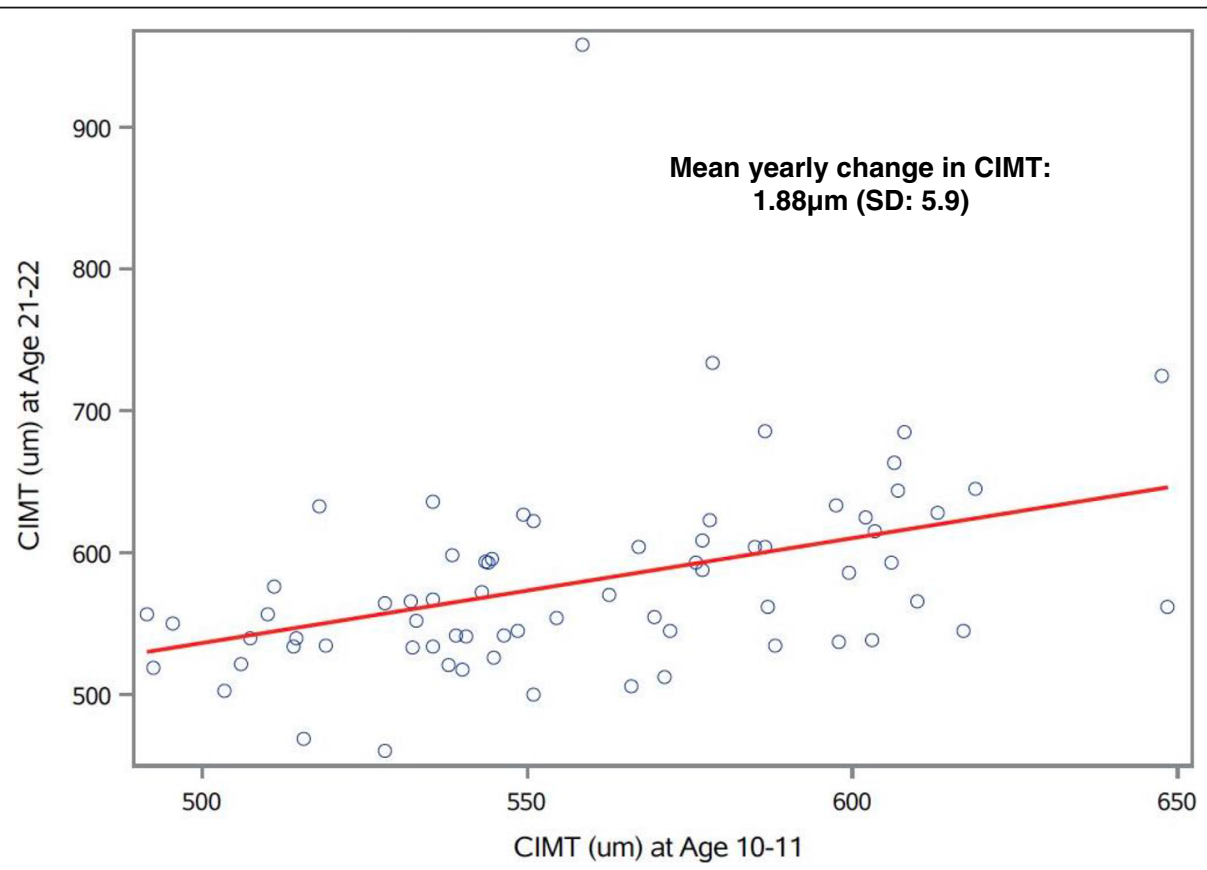

Fig. 1 Correlation plot of CIMT ultrasound measures over time $(N=70)$. Open circles represent CIMT $(\mu \mathrm{m})$ measurements obtained at age 10-11 years (x-axis) plotted against CIMT $(\mu \mathrm{m})$ measurements obtained from the same participant at age 21-22 years of age 
Table 2 Descriptive statistics of overall yearly rate of change in CIMT ( $\mu$ m/year) from childhood (age 10-11 years) to adulthood (age $21-22$ years) by participant characteristics $(N=70)$

\begin{tabular}{|c|c|c|c|c|}
\hline & $\mathrm{N}(\%)$ & Mean Rate of Change CIMT ( $\mu \mathrm{m} /$ year) & SD & $p$-value \\
\hline Sex & & & & 0.62 \\
\hline Male & $29(41.4)$ & 1.45 & 4.92 & \\
\hline Female & $41(58.6)$ & 2.18 & 6.50 & \\
\hline Race & & & & 0.60 \\
\hline White & $44(62.9)$ & 1.73 & 3.48 & \\
\hline More than one race & $14(20.0)$ & 1.30 & 4.05 & \\
\hline Other $^{\mathrm{b}}$ & $5(7.1)$ & 5.31 & 18.35 & \\
\hline Unknown/not reported & $7(10.0)$ & 1.50 & 6.17 & \\
\hline Ethnicity & & & & 0.26 \\
\hline Hispanic & $38(54.3)$ & 1.04 & 4.29 & \\
\hline Non-Hispanic & $30(42.8)$ & 3.14 & 7.24 & \\
\hline Unknown/not reported & $2(2.9)$ & -1.14 & 9.15 & \\
\hline Parental Educational Attainment & & & & 0.34 \\
\hline High school or less & $18(25.7)$ & 0.32 & 5.24 & \\
\hline Some college or technical school & $21(30.0)$ & 1.72 & 3.83 & \\
\hline Completed college or more & $31(44.3)$ & 2.89 & 7.16 & \\
\hline BMI category - child measurement & & & & 0.01 \\
\hline Underweight (<18.5) & $5(7.1)$ & 1.25 & 5.42 & \\
\hline Normal $(18.5$ to $<25)$ & $44(62.9)$ & 1.51 & 4.02 & \\
\hline Overweight ( 25 to <30) & $14(20.0)$ & 0.02 & 3.55 & \\
\hline Obese $(\geq 30)$ & $7(10.0)$ & 8.35 & 13.21 & \\
\hline BMI category - adult measurement & & & & 0.01 \\
\hline Underweight $(<18.5)$ & $3(4.3)$ & 2.74 & 1.32 & \\
\hline Normal $(18.5$ to $<25)$ & $42(60.0)$ & 1.05 & 4.29 & \\
\hline Overweight (25 to < 30) & $18(25.7)$ & 1.08 & 3.95 & \\
\hline Obese $(\geq 30)$ & $7(10.0)$ & 8.50 & 12.91 & \\
\hline Change in BMI category & & & & 0.27 \\
\hline Underweight/normal - no change & $40(57.1)$ & 1.47 & 4.16 & \\
\hline Overweight/obese - no change & $16(22.9)$ & 4.09 & 9.54 & \\
\hline Underweight/normal to overweight/obese & $9(12.9)$ & 1.51 & 4.16 & \\
\hline Overweight/obese to underweight/normal & $5(7.1)$ & -1.33 & 3.79 & \\
\hline Change Direction in BMI Category & & & & 0.37 \\
\hline Decrease & $10(14.2)$ & -0.10 & 3.70 & \\
\hline No change & $44(62.9)$ & 2.59 & 6.68 & \\
\hline Increase & $16(22.9)$ & 1.15 & 4.20 & \\
\hline Child Systolic Blood Pressure & & & & 0.14 \\
\hline Below 75th percentile $(<106 \mathrm{mmHg})$ & $52(74.3)$ & 1.27 & 3.91 & \\
\hline Above 75 th percentile $(\geq 106 \mathrm{mmHg})$ & $18(25.7)$ & 3.62 & 9.46 & \\
\hline Adult Systolic Blood Pressure & & & & 0.59 \\
\hline Below 75th percentile $(<111 \mathrm{mmHg})$ & $51(67.9)$ & 1.65 & 6.20 & \\
\hline Above 75 th percentile $(\geq 111 \mathrm{mmHg})$ & $19(27.1)$ & 2.50 & 4.95 & \\
\hline \multicolumn{4}{|l|}{ Change in Systolic Blood Pressure } & 0.42 \\
\hline
\end{tabular}


Table 2 Descriptive statistics of overall yearly rate of change in CIMT ( $\mu \mathrm{m} /$ year) from childhood (age 10-11 years) to adulthood (age 21-22 years) by participant characteristics $(N=70)$ (Continued)

\begin{tabular}{|c|c|c|c|c|}
\hline & $\mathrm{N}(\%)$ & Mean Rate of Change CIMT ( $\mu \mathrm{m} / \mathrm{year}$ ) & SD & $p$-value ${ }^{a}$ \\
\hline Below 75th percentile (<8.7 mmHg change) & $42(60.0)$ & 1.41 & 6.62 & \\
\hline Above 75 th percentile ( $\geq 8.7 \mathrm{mmHg}$ change) & $28(40.0)$ & 2.57 & 4.53 & \\
\hline Smoking status & & & & 0.14 \\
\hline Never smoked & $45(64.3)$ & 2.88 & 6.61 & \\
\hline Smoked but not in past 12 months & $15(21.4)$ & 0.59 & 4.12 & \\
\hline Smoked in past 12 months & $10(14.3)$ & -0.69 & 2.96 & \\
\hline Any family history of $\mathrm{CV}$ events ${ }^{\mathrm{C}}$ & & & & 0.19 \\
\hline No & $27(38.6)$ & 0.85 & 3.87 & \\
\hline Yes & $43(61.4)$ & 2.52 & 6.79 & \\
\hline
\end{tabular}

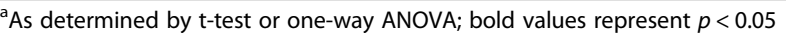

${ }^{b}$ Other includes Asian, Pacific Islander, Alaska Native and American Indian

'Events include hyperlipidemia (high cholesterol), hypertension (high blood pressure), stroke, coronary artery disease, and/or any other heart disease for any biological family members

$\left(\mathrm{PM}_{10}, \mathrm{PM}_{2.5}, \mathrm{O}_{3}\right.$, and $\left.\mathrm{NO}_{2}\right)$ and traffic-related nonfreeway NOx were not related to changes in CIMT. Further adjustment for additional potential confounders did not substantially change estimates or overall trends (Table S6).

We also observed higher attained CIMT in early adulthood in relation to childhood exposure to traffic density and traffic-related measures of NOx (Table 4). Total NOx and freeway NOx both were positively associated with attained CIMT at age 21-22 years, such that 1 SD increase in childhood traffic-related total NOx was associated with was associated with $20.60 \mu \mathrm{m}$ (95\% CI: 2.87, 38.36, $p=0.02$ ) in attained CIMT and a 1 SD increase in childhood traffic-related freeway $\mathrm{NO}_{\mathrm{x}}$ exposure was associated with $21.09 \mu \mathrm{m}$ (95\% CI: 3.33, 38.85, $p=0.02)$ in attained CIMT. We observed a $23.01 \mu \mathrm{m}$ (95\% CI: 6.38, 39.42; $p=0.007$ ) higher attained CIMT in early adulthood for each SD increase in traffic density. Ambient pollutants and non-freeway NOx were not related to attained CIMT in early adulthood.

In exploratory analyses stratified by sex, we observed somewhat greater increases in CIMT over time in female participants versus male participants, in relation to traffic-related NOx (Table S7). Among female participants, a 1 SD increase in childhood total $\mathrm{NO}_{\mathrm{x}}$ was associated with an average yearly increase of $3.07 \mu \mathrm{m}(95 \%$ CI: $0.83,5.38, p=0.009$ ) in CIMT over the follow-up period, as compared to males, for whom childhood total $\mathrm{NO}_{x}$ was associated with an average yearly increase of $1.12 \mu \mathrm{m}(95 \%$ CI: $-0.65,2.91, p=0.20)$ in CIMT. Similarly, freeway NOx was associated with greater changes in CIMT among females as compared to males. However, traffic density was associated with statistically significant yearly increases in CIMT in both females $2.51 \mu \mathrm{m}$ (95\% CI: $-0.21,4.81, p=0.03)$ and in males $1.62 \mu \mathrm{m}(95 \%$ CI: $0.06,3.24, p=0.04)$.

Table 3 Estimates of association between ambient and traffic-related air pollutants and rate of change in CIMT ( $\mu \mathrm{m})$ per year from childhood to adulthood, adjusted for personal smoking, adult BMI and parental education $(N=70)$

\begin{tabular}{lll}
\hline & Estimate $(\mathbf{9 5} \% \mathrm{Cl})$ per $\mathbf{1}$ SD increase in exposure ${ }^{\mathbf{a}}$ & $\boldsymbol{P}_{\text {-value }}$ \\
\hline Ambient Pollutants (monthly average) & & \\
Daily 8-h max $\mathrm{O}_{3}$ concentration $(\mathrm{ppb})$ & $-1.02(-2.41,0.36)$ & 0.14 \\
24-h average $\mathrm{PM}_{2.5}$ concentration $\left(\mu \mathrm{g} / \mathrm{m}^{3}\right)$ & $-0.40(-1.75,0.96)$ & 0.56 \\
24-h average $\mathrm{PM}_{10}$ concentration $\left(\mu \mathrm{g} / \mathrm{m}^{3}\right)$ & $-0.51(-1.85,0.85)$ & 0.46 \\
24-h average $\mathrm{NO}_{2}$ concentration $\left(\mu \mathrm{g} / \mathrm{m}^{3}\right)$ & $0.17(-1.19,1.53)$ & 0.81 \\
Local Traffic-Related Pollutants/Measures & & $\mathbf{0 . 0 0 3}$ \\
Total NOx $(\mathrm{ppb})$ & $2.17(0.78,3.56)$ & $\mathbf{0 . 0 0 2}$ \\
Freeway NOx $(\mathrm{ppb})$ & $2.24(0.84,3.63)$ & 0.39 \\
Non-Freeway NOx (ppb) & $0.60(-0.78,1.98)$ & $\mathbf{0 . 0 0 2}$ \\
Traffic Density (within $300 \mathrm{~m}$ buffer) & $2.11(0.79,3.43)$ &
\end{tabular}

${ }^{a}$ Estimates are each scaled to represent yearly change in CIMT relative to a 1 standard deviation (SD) increase in childhood exposure to the corresponding pollutant 
Table 4 Estimates of association between ambient and traffic-related air pollutants and adult attained ${ }^{a}$ CIMT ( $\mu$ m), adjusted for personal smoking, adult BMl, and parental education $(N=70)$

\begin{tabular}{lll}
\hline & Estimate $(\mathbf{9 5} \% \mathrm{Cl})$ per $\mathbf{1}$ SD increase in exposure ${ }^{\mathbf{b}}$ & $\boldsymbol{P}_{\text {-value }}$ \\
\hline Ambient Pollutants (monthly average) & & \\
Daily 8-h max $\mathrm{O}_{3}$ concentration $(\mathrm{ppb})$ & $-10.35(-27.54,6.83)$ & 0.23 \\
24-h average $\mathrm{PM}_{2.5}$ concentration $\left(\mu \mathrm{g} / \mathrm{m}^{3}\right)$ & $-1.62(-18.38,15.14)$ & 0.85 \\
24-h average $\mathrm{PM}_{10}$ concentration $\left(\mu \mathrm{g} / \mathrm{m}^{3}\right)$ & $-2.81(-19.54,13.90)$ & 0.74 \\
24-h average $\mathrm{NO}_{2}$ concentration $\left(\mu \mathrm{g} / \mathrm{m}^{3}\right)$ & $6.43(-10.30,23.16)$ & $\mathbf{0 . 4 5}$ \\
Local Traffic-Related Pollutants/Measures & & $\mathbf{0 . 0 2}$ \\
Total NOx (ppb) & $20.60(2.87,38.36)$ & $\mathbf{0 . 0 2}$ \\
Freeway NOx $(\mathrm{ppb})$ & $21.09(3.33,38.85)$ & 0.47 \\
Non-Freeway NOx (ppb) & $6.25(-10.84,23.33)$ & $\mathbf{0 . 0 0 7}$ \\
Traffic Density (within $300 \mathrm{~m}$ buffer) & $23.01(6.38,39.42)$ &
\end{tabular}

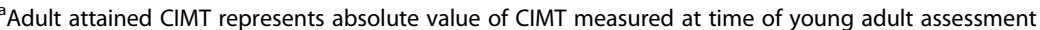

${ }^{b}$ Estimates are each scaled to represent a change in beta for a 1 standard deviation (SD) increase in exposure to the corresponding pollutant

\section{Discussion}

In this study of 70 young adults with repeated carotid artery ultrasound images from age 10-11 and age 21-22, we observed associations between traffic density and traffic-related NOx (total and freeway-related) with CIMT, a measure of subclinical atherosclerosis. Our results suggest that childhood exposure to local traffic-related air pollution is associated with greater rate of yearly change in CIMT from childhood to adulthood, as well as greater attained CIMT levels by age 21-22 with adjustment for adult BMI and personal smoking. Further, in exploratory analyses stratified by sex, somewhat greater yearly increases in CIMT were observed with total NOx and freeway NOx among female participants. However, sex-stratified analyses should be interpreted with caution given the small sample size in each group. Our results also suggest that individual factors, such as BMI, may influence early patterns of progression of subclinical atherosclerosis and cardiovascular health in early adulthood.

While overt CVD is rarely diagnosed until adulthood, early indicators of pathogenic processes can be observed in childhood [73]. Atherosclerosis is a lifelong process that begins in childhood and a number of studies, including many utilizing carotid artery ultrasound measures, have observed changes in childhood associated with later life cardiovascular health in adulthood [50, 74-82]. Air pollution is thought to promote CVD pathogenesis by affecting key cellular pathways involved in inflammation, vascular remodeling, lipid deposition, fibrosis and calcification, and studies among children and young adults have observed that air pollutant levels are related to greater inflammation, endothelial damage and oxidative stress [83-85]. In recent years, numerous epidemiological studies have provided strong evidence that exposure to air pollutants not only increases CVD incidence, but also accelerates atherosclerosis in adults $[8,9,14-27,32,35]$. Despite the considerable support linking air pollution and CVD in adults, very little is known about the origins of CVD in early stages during childhood and adolescence, particularly in relation to environmental exposures, such as air pollution. Even in this relatively small study population, we observed statistically significant changes in CIMT in relation to trafficrelated exposure markers in healthy young adults and while these changes may appear small, small increases in CIMT over the course of the lifetime may lead to greater thickening over time and greater long-term risk of CVD.

We found that residential traffic density and exposure to traffic-related NOx in childhood were related to greater changes in CIMT over time. While we previously found no association between traffic-related air pollution in early childhood and CIMT at age 10 years [21], a limited number of other studies have shown relationships between traffic-related exposures and early cardiovascular changes in children and young adults [21,36-39]. One study found increased carotid artery stiffness among 6-14 year old children living in close proximity $(<300 \mathrm{~m})$ to a highly-trafficked roadway, as compared to those living more than $300 \mathrm{~m}$ from the road, while a similar study found that children residing less than $100 \mathrm{~m}$ from a busy road had 15\% increased CIMT compared to those who lived further from traffic [37, 40]. Recent work found that exposures to $\mathrm{NO}_{2}, \mathrm{NO}_{\mathrm{x}}$ and $\mathrm{PM}$ were associated with decreased distensibility in children at age 5 [39]. Others have suggested that prenatal and early life may represent sensitive periods for air pollution exposure and cardiovascular health, and have observed associations between prenatal and early air pollution exposures and adverse changes in childhood cardiovascular risk factors, including CIMT, carotid artery stiffness, BP and BMI [21, 22, 36, 41-46]. Although a number of these prior studies observed associations with ambient air pollutants, including $\mathrm{O}_{3}$ and $\mathrm{PM}_{2.5}$, we did not observe any relationship between ambient pollutants and CIMT in our analysis [21, 22, 36, 42- 
44]. Instead, we found consistent associations with measures of more spatially variable and local exposure to traffic-related air pollution (CALINE4 NOx overall and from freeways and traffic density). Ambient air pollutants, assigned by interpolating from regulatory monitoring network data capture the regional, background levels of air pollution over the study area. Several sources contribute to these levels, and these sources could be emitted or formed locally or transported into a city's airshed from upwind sources for example (including traffic in the region). However, the ambient measures are not attributed to any specific source(s). They represent overall levels and are mainly capturing temporal variability in ambient air pollution (from all sources in an airshed). Whereas the traffic-related NOx estimates are calculated using a deterministic line source dispersion model (CALINE4), which captures the high spatial variability in traffic emissions from nearby roadways and their dispersion patterns.

Therefore, the traffic metrics model the contribution of traffic sources specifically (by road class) to $\mathrm{NOx}$ levels at residences and could be capturing the effects of the near-roadway air pollution mixture that is enriched in ultrafine and coarse particles, elemental and organic carbon, metals, nitrogen oxides and other tailpipe and non-tailpipe components of traffic emissions that have been shown to be associated with inflammation, oxidative stress and cardiovascular endpoints including CIMT [86-88]. In an analysis of PM samples collected within eight of the CHS communities, CALINE4 freeway NOx was a strong predictor of tailpipe (diesel) and non-tailpipe (abrasive vehicular emissions) particulate matter source contributions in the $\mathrm{PM}_{0.2}$ (quasi-ultrafine), $\mathrm{PM}_{2.5}$ (fine) and $\mathrm{PM}_{2.5-10}$ (coarse) size fractions [89]. Overall, our findings suggest the need to investigate characteristics of the near-roadway traffic mixture (e.g., chemical composition, size distribution, solubility, etc.) that could be driving these subclinical effects [90].

Importantly, childhood cardiovascular risk factors, including carotid artery stiffness, blood lipids, BP and BMI, have been associated with increases in CIMT in later life [47-50]. However, no studies have characterized changes in measures of subclinical atherosclerosis over time in younger populations, or the role of air pollutants in these changes. To put our results in context, we observed a change of $\sim 1.7 \mu \mathrm{m} /$ year change in CIMT associated with a $1 \mathrm{SD}$ increase in residential traffic density, which is very similar to previously observed change in CIMT of $3 \mu \mathrm{m}$ over a $\sim 2$ year period related to a $10 \mathrm{mmHg}$ increase in SBP in 14-18 year olds [91]. The rate of change we observed with traffic-related exposure also was similar to previously observed associations with age in a somewhat older cohort of young adults over six years of follow up in the Young Finns study (ages 24-39 at baseline) [92]. Age was associated with a total CIMT change of $14.5 \mu \mathrm{m}$ over follow up, equivalent to approximately a $2.4 \mu \mathrm{m} /$ year change in CIMT [92]. To our knowledge, ours is the first study to examine changes over time in CIMT in relation to air pollution during the critical transition period from childhood into adulthood when many lifelong health patterns and habits become established.

In our study, we observed that higher BMI in both childhood and adulthood were related to a significant mean increase in CIMT over time in univariate analyses. Other studies have observed relationships between cardiovascular risk factors, including BMI, and atherosclerosis-related vascular remodeling and arterial stiffness in adults and increasingly, the presence of these risk factors in childhood has been linked to measurements of atherosclerosis in adulthood [3, 47, 48, 74, 9395]. A combined study of 4 international cohorts found that BMI, BP, smoking and blood lipids were independent predictors of CIMT in early adulthood [49]. Some risk factors have also been associated with CIMT in children, including BP, family history of hypertension, and markers of insulin resistance and exposure to tobacco smoke, suggesting that cardiovascular stressors may lead to early subclinical atherosclerosis [81, 82, 96-101]. While BP and family history of CVD were not associated with statistically significant changes in CIMT in the current study, we will continue to explore these risk factors in future work. Overall, little is known about how individual factors may influence changes in CIMT in the transition from childhood to adulthood and further investigation is warranted.

Our study has a number of strengths. We were able to examine changes in measures of subclinical atherosclerosis over time in a unique dataset from the CHS that captures residential mobility over childhood and includes detailed ambient and traffic-related air pollution exposure estimates, in addition to repeated carotid artery ultrasound measures in childhood and in early adulthood. One key advantage of this study is that the same ultrasound imaging technician who performed the initial carotid artery ultrasound imaging of CHS participants at age 10-11 conducted all repeat measures for this project, eliminating inter-technician differences in image acquisition and providing consistency across our time points, despite the intervening years. Further, the imaging technician had access to prior images to measure within the same anatomical landmarks. Imaging technicians and processors were blinded to all exposure information to avoid biasing outcome measurements. Our study also has some limitations. First, our sample size in this study was limited and we were not well powered to investigate effect modification by potentially important factors, such as BMI and sex. Despite the small sample size, we observed consistent, statistically significant associations between traffic-related exposures and CIMT 
and suggestive differences by sex in stratified analyses. However, these results must be interpreted with caution given the small samples size and future studies with a larger sample will be able to more fully evaluate the possible impact of other factors on change in CIMT. We also cannot rule out unmeasured confounding and it is possible that other factors, such as dietary intake and physical activity may impact patterns of subclinical atherosclerosis progression over time and should be taken into account in future studies. Also, we adjusted for socioeconomic status (SES) using parental education as a proxy variable, which may not fully capture SES variability or changes since time of assessment of this variable in childhood. Given the age of these participants, many are still continuing their education (either full or parttime) and may live with parents or roommates, making assessment of SES of the participant by more traditional indicators, such as educational attainment or household income, unreliable measures of SES. While this pilot study was conducted among a convenience sample of 70 CHS participants, the distribution of original enrollment communities and demographic characteristics of these participants were similar to the overall distributions of the original cohort of CIMT participants. Further, we did not have complete modeled air pollution data beyond age 10 years for all participants at the time of this analysis to account for lifetime exposures. However, exploratory analyses that included air pollution exposures up to age 16 among those with these exposure data (not shown) did not substantially alter our findings and future work will further explore lifetime air pollutant exposures.

\section{Conclusions}

In conclusion, our study results suggest that trafficrelated air pollutants may be associated with adverse changes in CIMT, a measure of subclinical atherosclerosis, over time in a population of young adults who have been followed since childhood. Such increases in progression of CIMT by early adulthood could indicate greater CIMT thickening over time and may be relevant in predicting long-term CVD risk. While our results must be interpreted with caution given the limited sample size, the statistically significant associations between traffic-related air pollutants and change in CIMT suggest important changes during this critical lifestage that warrant further studies with larger study samples. Early detection of initial vascular changes in childhood into young adulthood with carotid artery ultrasound measurements has the potential to not only improve our understanding of CVD pathogenesis as it relates to air pollution exposures, but also facilitates identification of children at risk for CVD later in life.

\section{Abbreviations}

CVD: Cardiovascular disease; CIMT: Carotid intima media thickness;

CHS: Children's Health Study; $\mathrm{O}_{3}$ : Ozone; $\mathrm{NO}_{2}$ : Nitrogen dioxide;

$\mathrm{NO}_{x}$ : Nitrogen oxides; PM: Particulate matter

\section{Supplementary Information}

The online version contains supplementary material available at https://doi. org/10.1186/s12940-021-00726-x.

\section{Additional file 1.}

\section{Acknowledgements}

We would like to thank the CHS staff and ARU technicians for their role in data collection, as well as Wendy Mack for her advice on CIMT measurement data. We also thank our CHS participants for their continued interest and participation.

\section{Authors' contributions}

SFF conceptualized this study with input on data collection and study design from $\mathrm{CB}, \mathrm{TB}, \mathrm{EA}$, and $\mathrm{HH}$. $\mathrm{HH}$ led collection of CIMT data and provided valuable input on interpretation of ultrasound results. $\mathrm{RH}$ and $\mathrm{FL}$ provided air pollution exposure estimates. SFF analyzed and interpreted the data, with assistance from WJG, RH and PD. All authors read and approved the final manuscript.

\section{Funding}

Funding for this study was provided by NIH grant UH3OD023287 and pilot grants from the Southern California Environmental Sciences Center (P30ES007048) and the Southern California Clinical and Translational Sciences Institute (NIH NCATS grants UL1TR001855 and UL1TR000130). Dr. Farzan is also supported by a NIEHS Pathway to Independence Grant (R00 ES024144). The funding agencies that supported this work had no role in the planning, design or execution of this study, nor any role in data analysis or manuscript preparation.

\section{Availability of data and materials}

The datasets used and analyzed during the current study are available from the corresponding author on reasonable request.

\section{Declarations}

Ethics approval and consent to participate

All participants provided written informed consent prior to enrollment. All protocols and study materials were approved by the University of Southern California's Institutional Review Board.

\section{Consent for publication}

Not applicable. No individual level data are presented.

Competing interests

The authors declare that they have no competing interests.

\section{Author details}

${ }^{1}$ Department of Preventive Medicine, Keck School of Medicine of University of Southern California, 2001 N. Soto Street, Los Angeles, CA 90089, USA. ${ }^{2}$ Sonoma Technology Inc., Petaluma, CA, USA. ${ }^{3}$ Department of Medicine, Keck School of Medicine of University of Southern California, Los Angeles, CA 90089, USA. ${ }^{4}$ Atherosclerosis Research Unit, University of Southern California, Los Angeles, CA 90089, USA.

Received: 29 January 2021 Accepted: 8 April 2021

Published online: 14 April 2021

\section{References}

1. World Health Organization. Causes of death 2008. Geneva: World Health Organization; 2008.

2. Yusuf S, Reddy S, Ounpuu S, Anand S. Global burden of cardiovascular diseases: part I: general considerations, the epidemiologic transition, risk 
factors, and impact of urbanization. Circulation. 2001;104(22):2746-53. https://doi.org/10.1161/hc4601.099487.

3. World Health Organization. Cardiovascular Disease Fact Sheet. http://www. who.int/mediacentre/factsheets/fs317/en/. Accessed 01 Apr 2021.

4. Willett WC. Balancing life-style and genomics research for disease prevention. Science. 2002;296(5568):695-8. https://doi.org/10.1126/science.1 071055 .

5. Tellez-Plaza M, Navas-Acien A, Menke A, Crainiceanu CM, Pastor-Barriuso R, Guallar E. Cadmium exposure and all-cause and cardiovascular mortality in the U.S. general population. Environ Health Perspect. 2012;120(7):1017-22. https://doi.org/10.1289/ehp.1104352.

6. Martin D, Glass TA, Bandeen-Roche K, Todd AC, Shi W, Schwartz BS, Association of blood lead and tibia lead with blood pressure and hypertension in a community sample of older adults. Am J Epidemiol. 2006; 163(5):467-78. https://doi.org/10.1093/aje/kwj060.

7. Guallar E, Sanz-Gallardo MI, van't Veer P, Bode P, Aro A, Gomez-Aracena J, et al. Mercury, fish oils, and the risk of myocardial infarction. N Engl J Med. 2002;347(22):1747-54. https://doi.org/10.1056/NEJMoa020157.

8. Dockery DW, Pope CA 3rd, Xu X, Spengler JD, Ware JH, Fay ME, et al. An association between air pollution and mortality in six U.S. cities. N Engl J Med. 1993;329(24):1753-9. https://doi.org/10.1056/NEJM199312093292401.

9. Pope CA, Burnett RT, Thurston GD, Thun MJ, Calle EE, Krewski D, et al. Cardiovascular mortality and long-term exposure to particulate air pollution: epidemiological evidence of general pathophysiological pathways of disease. Circulation. 2004;109(1):71-7. https://doi.org/10.1161/01.CIR.00001 08927.80044.7F.

10. Cosselman KE, Navas-Acien A, Kaufman JD. Environmental factors in cardiovascular disease. Nat Rev Cardiol. 2015;12(11):627-42. https://doi.org/1 0.1038/nrcardio.2015.152.

11. Schwartz J. Air pollution and hospital admissions for heart disease in eight U.S.Counties. Epidemiology. 1999;10(1):17-22. https://doi.org/10.1097/00001 648-199901000-00005.

12. Mann JT, IB; Lurmann, FW; Segal, M; Quesenberry, CP; Lug, MM; Shan, J; Van Den Eeden, SK: The effect of air pollution on hospital admissions for ischemic heart disease in persons with secondary diagnoses for congestive heart failure or arrhythmia. Environ Health Perspect 2002, 110:1247-1252, 12, doi: https://doi.org/10.1289/ehp.021101247.

13. Schwartz J. Air pollution and blood markers of cardiovascular risk. Environ Health Perspect. 2001;109(Suppl 3):405-9.

14. Thurston GD, Ahn J, Cromar KR, Shao Y, Reynolds HR, Jerrett M, et al. Ambient particulate matter air pollution exposure and mortality in the $\mathrm{NIH}$ AARP diet and health cohort. Environ Health Perspect. 2016;124(4):484-90. https://doi.org/10.1289/ehp.1509676.

15. Brook RF, B; Cascio,W; Hong,Y; Howard,G; Lipsett,M; Luepker,R; Mittleman,M; Samet, J; Smith,S; Tager,l,: Air pollution and Cardiosvascular disease. A statement for healthcare professionals from the expert panel on population and prevention science of the American Heart Association. Ciruclation 2004, 109:2655-2671, 21, doi: https://doi.org/10.1161/01.CIR.0000128587.30041.C8.

16. Pope A, Thun M, Namboodiri M, Dockery D, Evans J, Speizer F, et al. Particulate air pollution as a predictor of mortality in a prospective study of U.S.Adults. Am J Respir Crit Care Med. 1995;151(3):669-74. https://doi.org/1 0.1164/ajrccm/151.3_Pt_1.669.

17. Hoek G, Brunekreef B, Goldbohm S, Fischer P, van den Brandt PA Association between mortality and indicators of traffic-related air pollution in the Netherlands: a cohort study. Lancet. 2002;360(9341):1203-9. https:// doi.org/10.1016/S0140-6736(02)11280-3.

18. Samet JM, Dominici F, Curriero FC, Coursac I, Zeger SL. Fine particulate air pollution and mortality in 20 U.S. cities, 1987-1994. N Engl J Med. 2000; 343(24):1742-9.

19. Schwartz J, Laden F, Zanobetti A. The concentration-response relation between PM(2.5) and daily deaths. Environ Health Perspect. 2002;110(10): 1025-9. https://doi.org/10.1289/ehp.021101025.

20. Suwa T, Hogg JC, Quinlan KB, Ohgami A, Vincent R, van Eeden SF. Particulate air pollution induces progression of atherosclerosis. J Am Coll Cardiol. 2002;39(6):935-42. https://doi.org/10.1016/S0735-1097(02)01715-1.

21. Breton CV, Mack WJ, Yao J, Berhane K, Amadeus M, Lurmann F, et al. Prenatal air pollution exposure and early cardiovascular phenotypes in young adults. Plos One. 2016;11(3):e0150825. https://doi.org/10.1371/journal. pone. 0150825

22. Breton CV, Wang X, Mack WJ, Berhane K, Lopez M, Islam TS, et al. Childhood air pollutant exposure and carotid artery intima-media thickness in young adults. Circulation. 2012;126(13):1614-20. https://doi.org/10.1161/CIRCULA TIONAHA. 112.096164

23. Akintoye E, Shi L, Obaitan I, Olusunmade M, Wang Y, Newman JD, et al. Association between fine particulate matter exposure and subclinical atherosclerosis: a meta-analysis. Eur J Prev Cardiol. 2016;23(6):602-12. https://doi.org/10.1177/2047487315588758.

24. Kaufman JD, Adar SD, Barr RG, Budoff M, Burke GL, Curl CL, et al. Association between air pollution and coronary artery calcification within six metropolitan areas in the USA (the multi-ethnic study of atherosclerosis and air pollution): a longitudinal cohort study. Lancet. 2016;388(10045):696-704. https://doi.org/10.1016/S0140-6736(16)00378-0.

25. Wang Y, Wellenius GA, Hickson DA, Gjelsvik A, Eaton CB, Wyatt SB. Residential proximity to traffic-related pollution and atherosclerosis in 4 vascular beds among African-American adults: results from the Jackson heart study. Am J Epidemiol. 2016;184(10):732-43. https://doi.org/10.1093/a je/kww080.

26. Chan SH, Van Hee VC, Bergen S, Szpiro AA, DeRoo LA, London SJ, et al. Long-term air pollution exposure and blood pressure in the sister study. Environ Health Perspect. 2015;123(10):951-8. https://doi.org/10.1289/ehp.14 08125.

27. Kunzli N, Jerrett M, Mack WJ, Beckerman B, LaBree L, Gilliland F, et al. Ambient air pollution and atherosclerosis in Los Angeles. Environ Health Perspect. 2005;113(2):201-6. https://doi.org/10.1289/ehp.7523.

28. Hodis HN, Mack WJ, LaBree L, Selzer RH, Liu CR, Liu CH, et al. The role of carotid arterial intima-media thickness in predicting clinical coronary events. Ann Intern Med. 1998;128(4):262-9. https://doi.org/10.7326/0003-4819-12 8-4-199802150-00002.

29. Polak JF, Pencina MJ, Pencina KM, O'Donnell CJ, Wolf PA, D'Agostino RB Sr. Carotid-wall intima-media thickness and cardiovascular events. N Engl J Med. 2011;365(3):213-21. https://doi.org/10.1056/NEJMoa1012592.

30. Vanhoutte PM. Endothelial dysfunction: the first step toward coronary arteriosclerosis. Circ J. 2009;73(4):595-601. https://doi.org/10.1253/circj.CJ08-1169.

31. Hoffmann B, Moebus S, Mohlenkamp S, Stang A, Lehmann N, Dragano N et al. Residential exposure to traffic is associated with coronary atherosclerosis. Circulation. 2007;116(5):489-96. https://doi.org/10.1161/ CIRCULATIONAHA.107.693622.

32. Kunzli N, Jerrett M, Garcia-Esteban R, Basagana X, Beckermann B, Gilliland F, et al. Ambient air pollution and the progression of atherosclerosis in adults. Plos One. 2010;5(2):e9096. https://doi.org/10.1371/journal.pone.0009096.

33. Perez L, Wolf K, Hennig F, Penell J, Basagana X, Foraster M, et al. Air pollution and atherosclerosis: a cross-sectional analysis of four European cohort studies in the ESCAPE study. Environ Health Perspect. 2015;123(6): 597-605. https://doi.org/10.1289/ehp.1307711.

34. Rivera M, Basagana X, Aguilera I, Foraster M, Agis D, de Groot E, et al. Association between long-term exposure to traffic-related air pollution and subclinical atherosclerosis: the REGICOR study. Environ Health Perspect. 2013;121(2):223-30. https://doi.org/10.1289/ehp.1205146.

35. Adar SD, Sheppard L, Vedal S, Polak JF, Sampson PD, Diez Roux AV, et al. Fine particulate air pollution and the progression of carotid intima-medial thickness: a prospective cohort study from the multi-ethnic study of atherosclerosis and air pollution. Plos Med. 2013;10(4):e1001430. https://doi. org/10.1371/journal.pmed.1001430.

36. Breton CV, Yao J, Millstein J, Gao L, Siegmund KD, Mack W, et al. Prenatal air pollution exposures, DNA methyl Transferase genotypes, and associations with newborn LINE1 and Alu methylation and childhood blood pressure and carotid intima-media thickness in the Children's health study. Environ Health Perspect. 2016;124(12):1905-12. https://doi.org/10.1289/EHP181.

37. Iannuzzi A, Verga MC, Renis M, Schiavo A, Salvatore V, Santoriello C, et al. Air pollution and carotid arterial stiffness in children. Cardiol Young. 2010;20(2): 186-90. https://doi.org/10.1017/S1047951109992010.

38. Lenters V, Uiterwaal CS, Beelen R, Bots ML, Fischer P, Brunekreef B, et al. Longterm exposure to air pollution and vascular damage in young adults. Epidemiology. 2010;21(4):512-20. https:/doi.org/10.1097/EDE.0b013e3181dec3a7.

39. Ntarladima AM, Vaartjes I, Grobbee DE, Dijst M, Schmitz O, Uiterwaal C, et al. Relations between air pollution and vascular development in 5-year old children: a cross-sectional study in the Netherlands. Environ Health. 2019; 18(1):50. https://doi.org/10.1186/s12940-019-0487-1.

40. Armijos RX, Weigel MM, Myers OB, Li WW, Racines M, Berwick M. Residential exposure to urban traffic is associated with increased carotid intima-media thickness in children. J Environ Public Health. 2015;2015:713540. 
41. Kim JS, Alderete TL, Chen Z, Lurmann F, Rappaport E, Habre R, et al. Longitudinal associations of in utero and early life near-roadway air pollution with trajectories of childhood body mass index. Environ Health. 2018;17(1):64. https://doi.org/10.1186/s12940-018-0409-7.

42. Zhang M, Mueller NT, Wang H, Hong X, Appel L, Wang X. Maternal exposure to ambient particulate matter $</=2.5$ microm during pregnancy and the risk for high blood pressure in childhood. Hypertension. 2018;72(1): 194-201. https://doi.org/10.1161/HYPERTENSIONAHA.117.10944.

43. Zhang Z, Dong B, Li S, Chen G, Yang Z, Dong Y, et al. Exposure to ambient particulate matter air pollution, blood pressure and hypertension in children and adolescents: a national cross-sectional study in China. Environ Int. 2019; 128:103-8. https://doi.org/10.1016/j.envint.2019.04.036.

44. Chiu YM, Hsu HL, Wilson A, Coull BA, Pendo MP, Baccarelli A, et al. Prenatal particulate air pollution exposure and body composition in urban preschool children: examining sensitive windows and sex-specific associations. Environ Res. 2017;158:798-805. https://doi.org/10.1016/j.envres.2017.07.026.

45. Magnussen CG, Smith KJ, Juonala M. When to prevent cardiovascular disease? As early as possible: lessons from prospective cohorts beginning in childhood. Curr Opin Cardiol. 2013;28(5):561-8. https://doi.org/10.1097/HCO. Ob013e32836428f4.

46. Sanders AP, Saland JM, Wright RO, Satlin L. Perinatal and childhood exposure to environmental chemicals and blood pressure in children: a review of literature 2007-2017. Pediatr Res. 2018;84(2):165-80. https://doi. org/10.1038/s41390-018-0055-3.

47. Ceponiene I, Klumbiene J, Tamuleviciute-Prasciene E, Motiejunaite J, Sakyte E, Ceponis J, et al. Associations between risk factors in childhood (12-13 years) and adulthood (48-49 years) and subclinical atherosclerosis: the Kaunas cardiovascular risk cohort study. BMC Cardiovasc Disord. 2015;15(1): 89. https://doi.org/10.1186/s12872-015-0087-0.

48. Ferreira I, van de Laar RJ, Prins MH, Twisk JW, Stehouwer CD. Carotid stiffness in young adults: a life-course analysis of its early determinants: the Amsterdam growth and health longitudinal study. Hypertension. 2012;59(1): 54-61. https://doi.org/10.1161/HYPERTENSIONAHA.110.156109.

49. Koskinen J, Juonala M, Dwyer T, Venn A, Thomson R, Bazzano L, et al. Impact of lipid measurements in youth in addition to conventional clinicbased risk factors on predicting preclinical atherosclerosis in adulthood: international childhood cardiovascular cohort consortium. Circulation. 2018; 137(12):1246-55. https://doi.org/10.1161/CIRCULATIONAHA.117.029726.

50. Li S, Chen W, Srinivasan SR, Bond MG, Tang R, Urbina EM, et al. Childhood cardiovascular risk factors and carotid vascular changes in adulthood: the Bogalusa heart study. JAMA. 2003;290(17):2271-6. https://doi.org/10.1001/ja ma.290.17.2271.

51. Berhane K, Chang CC, McConnell R, Gauderman WJ, Avol E, Rapapport E, et al. Association of Changes in air quality with Bronchitic symptoms in children in California, 1993-2012. JAMA. 2016;315(14):1491-501. https://doi. org/10.1001/jama.2016.3444.

52. Gauderman WJ, Urman R, Avol E, Berhane K, McConnell R, Rappaport E, et al. Association of improved air quality with lung development in children. N Engl J Med. 2015;372(10):905-13. https://doi.org/10.1056/NEJMoa1414123.

53. Gauderman WJ, Avol E, Gilliland F, Vora H, Thomas D, Berhane K, et al. The effect of air pollution on lung development from 10 to 18 years of age. $\mathrm{N}$ Engl J Med. 2004;351(11):1057-67. https://doi.org/10.1056/NEJMoa040610.

54. Gauderman WJ, Vora H, McConnell R, Berhane K, Gilliland F, Thomas D, et al. Effect of exposure to traffic on lung development from 10 to 18 years of age: a cohort study. Lancet. 2007;369(9561):571-7. https://doi.org/10.1016/ S0140-6736(07)60037-3.

55. Peters JM, Avol E, Navidi W, London SJ, Gauderman WJ, Lurmann F, et al. A study of twelve Southern California communities with differing levels and types of air pollution. I. Prevalence of respiratory morbidity. Am J Respir Crit Care Med. 1999;159(3):760-7. https://doi.org/10.1164/ajrccm.159.3.9804143.

56. McConnell R, Berhane K, Yao L, Jerrett M, Lurmann F, Gilliland F, et al. Traffic, susceptibility, and childhood asthma. Environ Health Perspect. 2006;114(5): 766-72. https://doi.org/10.1289/ehp.8594.

57. National Center for Health Statistics. NHANES 2017-2018 procedure manuals: anthropometry (body measures). Atlanta: Centers for Disease Control; 2020

58. Centers for Disease Control. Body Mass Index (BMI). https://www.cdc.gov/ healthyweight/assessing/bmi/. Accessed 01 Apr 2021.

59. Selzer RH, Hodis HN, Kwong-Fu H, Mack WJ, Lee PL, Liu CR, Liu CH: Evaluation of computerized edge tracking for quantifying intima-media thickness of the common carotid artery from B-mode ultrasound images.
Atherosclerosis 1994, 111(1):1-11, 1, doi: https://doi.org/10.1016/0021-91 50(94)90186-4.

60. Selzer RH, Mack WJ, Lee PL, Kwong-Fu H, Hodis HN. Improved common carotid elasticity and intima-media thickness measurements from computer analysis of sequential ultrasound frames. Atherosclerosis. 2001;154(1):185-93. https://doi.org/10.1016/S0021-9150(00)00461-5.

61. Hodis HN, Mack WJ, Shoupe D, Azen SP, Stanczyk FZ, Hwang-Levine J, et al. Methods and baseline cardiovascular data from the early versus late intervention trial with estradiol testing the menopausal hormone timing hypothesis. Menopause. 2015;22(4):391-401. https://doi.org/10.1097/GME. 0000000000000343

62. Hodis HN, Mack WJ, Dustin L, Mahrer PR, Azen SP, Detrano R, et al. Highdose $B$ vitamin supplementation and progression of subclinical atherosclerosis: a randomized controlled trial. Stroke. 2009;40(3):730-6. https://doi.org/10.1161/STROKEAHA.108.526798.

63. Mack WJ, LaBree L, Liu C, Selzer RH, Hodis HN. Correlations between measures of atherosclerosis change using carotid ultrasonography and coronary angiography. Atherosclerosis. 2000;150(2):371-9. https://doi.org/1 0.1016/S0021-9150(99)00383-4

64. Wong DW, Yuan L, Perlin SA. Comparison of spatial interpolation methods for the estimation of air quality data. J Expo Anal Environ Epidemiol. 2004; 14(5):404-15. https://doi.org/10.1038/sj.jea.7500338.

65. Benson P. CALINE4-a dispersion model for predicting air pollutant concentrations near roadways. Sacramento: California Department of Transportation; 1989

66. Franklin M, Vora H, Avol E, McConnell R, Lurmann F, Liu F, et al. Predictors of intra-community variation in air quality. J Expo Sci Environ Epidemiol. 2012;22(2):135-47. https://doi.org/10.1038/jes.2011.45.

67. Benson PE. A review of the development and application of the Caline3 and Caline4 models. Atmos Environ B-Urb. 1992;26(3):379-90. https://doi. org/10.1016/0957-1272(92)90013-I.

68. Fruin SA, Hudda N, Sioutas C, Delfino RJ. Predictive model for vehicle air exchange rates based on a large, representative sample. Environ Sci Technol. 2011:45(8):3569-75. https://doi.org/10.1021/es103897u.

69. Westerdahl D, Fruin S, Sax T, Fine P, Sioutas C. Mobile platform measurements of ultrafine particles and associated pollutant concentrations on freeways and residential streets in Los Angeles. Atmos Environ. 2005; 39(20):3597-610. https://doi.org/10.1016/j.atmosenv.2005.02.034

70. Zhu YF, Hinds WC, Kim S, Shen S, Sioutas C. Study of ultrafine particles near a major highway with heavy-duty diesel traffic. Atmos Environ. 2002;36(27): 4323-35. https://doi.org/10.1016/S1352-2310(02)00354-0.

71. Zhu YF, Kuhn T, Mayo P, Hinds WC. Comparison of daytime and nighttime concentration profiles and size distributions of ultrafine particles near a major highway. Environ Sci Technol. 2006;40(8):2531-6. https://doi.org/10.1 021/es0516514

72. Dalla Pozza R, Ehringer-Schetitska D, Fritsch P, Jokinen E, Petropoulos A, Oberhoffer $\mathrm{R}$, et al. Intima media thickness measurement in children: a statement from the Association for European Paediatric Cardiology (AEPC) working group on cardiovascular prevention endorsed by the Association for European Paediatric Cardiology. Atherosclerosis. 2015;238(2):380-7. https://doi.org/10.1016/j.atherosclerosis.2014.12.029.

73. Louisiana State Medical Center. Cardiovascular Profile of 15,000 Children of School Age in Three Communities, 1971-1975. U.S: Department of Health, Education, and Welfare, Public Health Service, National Institutes of Health, National Heart, Lung, and Blood Institute; 1978.

74. Berenson GS, Srinivasan SR, Bao W, Newman WP 3rd, Tracy RE, Wattigney WA. Association between multiple cardiovascular risk factors and atherosclerosis in children and young adults. The Bogalusa heart study. N Engl J Med. 1998; 338(23):1650-6. https://doi.org/10.1056/NEJM199806043382302.

75. Berenson GS, Srinivasan SR, Hunter SM, Nicklas TA, Freedman DS, Shear CL, et al. Risk factors in early life as predictors of adult heart disease: the Bogalusa heart study. Am J Med Sci. 1989;298(3):141-51. https://doi.org/10.1 097/00000441-198909000-00001.

76. Davis PH, Dawson JD, Riley WA, Lauer RM. Carotid intimal-medial thickness is related to cardiovascular risk factors measured from childhood through middle age: the Muscatine study. Circulation. 2001;104(23):2815-9. https:// doi.org/10.1161/hc4601.099486.

77. Hartiala O, Magnussen CG, Kajander S, Knuuti J, Ukkonen H, Saraste A, et al. Adolescence risk factors are predictive of coronary artery calcification at middle age: the cardiovascular risk in young Finns study. J Am Coll Cardiol. 2012;60(15):1364-70. https://doi.org/10.1016/j.jacc.2012.05.045. 
78. Juonala M, Jarvisalo MJ, Maki-Torkko N, Kahonen M, Viikari JS, Raitakari OT. Risk factors identified in childhood and decreased carotid artery elasticity in adulthood: the cardiovascular risk in young Finns study. Circulation. 2005; 112(10):1486-93. https://doi.org/10.1161/CIRCULATIONAHA.104.502161

79. Palve KS, Pahkala K, Magnussen CG, Koivistoinen T, Juonala M, Kahonen M, et al. Association of physical activity in childhood and early adulthood with carotid artery elasticity 21 years later: the cardiovascular risk in young Finns study. J Am Heart Assoc. 2014;3(2):e000594. https://doi.org/10.1161/JA HA.113.000594.

80. Raitakari OT, Juonala M, Kahonen M, Taittonen L, Laitinen T, Maki-Torkko N, et al. Cardiovascular risk factors in childhood and carotid artery intimamedia thickness in adulthood: the cardiovascular risk in young Finns study. JAMA. 2003:290(17):2277-83. https://doi.org/10.1001/jama.290.17.2277.

81. Knoflach M, Kiechl S, Penz D, Zangerle A, Schmidauer C, Rossmann A, et al. Cardiovascular risk factors and atherosclerosis in young women atherosclerosis risk factors in female youngsters (ARFY study). Stroke. 2009; 40(4):1063-9. https://doi.org/10.1161/STROKEAHA.108.525675.

82. Caserta CA, Pendino GM, Amante A, Vacalebre C, Fiorillo MT, Surace P, et al. Cardiovascular risk factors, nonalcoholic fatty liver disease, and carotid artery intima-media thickness in an adolescent population in southern Italy. Am J Epidemiol. 2010;171(11):1195-202. https://doi.org/10.1093/aje/kwq073.

83. Calderon-Garciduenas L, Villarreal-Calderon R, Valencia-Salazar G, HenriquezRoldan C, Gutierrez-Castrellon P, Torres-Jardon R, et al. Systemic inflammation, endothelial dysfunction, and activation in clinically healthy children exposed to air pollutants. Inhal Toxicol. 2008;20(5):499-506. https:// doi.org/10.1080/08958370701864797.

84. Chuang KJ, Chan CC, Su TC, Lee CT, Tang CS. The effect of urban air pollution on inflammation, oxidative stress, coagulation, and autonomic dysfunction in young adults. Am J Respir Crit Care Med. 2007;176(4):370-6. https://doi.org/10.1164/rccm.200611-16270C.

85. Kelishadi R, Poursafa P. A review on the genetic, environmental, and lifestyle aspects of the early-life origins of cardiovascular disease. Cur Problems Pediatr Adolesc Health Care. 2014;44(3):54-72. https://doi.org/10.1016/j. cppeds.2013.12.005.

86. Sun M, Kaufman JD, Kim SY, Larson TV, Gould TR, Polak JF, et al. Particulate matter components and subclinical atherosclerosis: common approaches to estimating exposure in a multi-ethnic study of atherosclerosis crosssectional study. Environ Health. 2013;12(1):39. https://doi.org/10.1186/1476069X-12-39.

87. Delfino RJ, Sioutas C, Malik S. Potential role of ultrafine particles in associations between airborne particle mass and cardiovascular health. Environ Health Persp. 2005;113(8):934-46. https://doi.org/10.1289/ehp.7938.

88. Downward GS, van Nunen E, Kerckhoffs J, Vineis P, Brunekreef B, Boer JMA, et al. Long-term exposure to ultrafine particles and incidence of cardiovascular and cerebrovascular disease in a prospective study of a Dutch cohort. Environ Health Perspect. 2018;126(12):127007. https://doi. org/10.1289/EHP3047.

89. Habre R, Girguis M, Urman R, Fruin S, Lurmann F, Shafer M, et al. Contribution of tailpipe and non-tailpipe traffic sources to quasi-ultrafine, Fine and coarse particulate matter in Southern California. J Air Waste Manag Assoc. 202;71(2):209-30.

90. Brook RD, Rajagopalan S, Pope CA 3rd, Brook JR, Bhatnagar A, Diez-Roux AV, et al. Particulate matter air pollution and cardiovascular disease: an update to the scientific statement from the American Heart Association. Circulation. 2010;121(21):2331-78. https://doi.org/10.1161/CIR.0b013e3181dbece1.

91. Staudt A, Stock K, Gande N, Bernar B, Hochmayr C, Pechlaner R, et al. Impact of lifestyle and cardiovascular risk factors on early atherosclerosis in a large cohort of healthy adolescents: the early vascular ageing (EVA)-Tyrol study. Atherosclerosis. 2020;305:26-33. https://doi.org/10.1016/j.atherosclerosis.202 0.05.011.

92. Koskinen J, Kahonen M, Viikari JS, Taittonen L, Laitinen T, Ronnemaa T, et al. Conventional cardiovascular risk factors and metabolic syndrome in predicting carotid intima-media thickness progression in young adults: the cardiovascular risk in young Finns study. Circulation. 2009;120(3):229-36. https://doi.org/10.1161/CIRCULATIONAHA.108.845065.

93. Ji X, Leng XY, Dong $Y, M a Y H, X u$ W, Cao XP, et al. Modifiable risk factors for carotid atherosclerosis: a meta-analysis and systematic review. Ann Transl Med. 2019;7(22):632. https://doi.org/10.21037/atm.2019.10.115.

94. Newman WP 3rd, Freedman DS, Voors AW, Gard PD, Srinivasan SR, Cresanta \lrcorner , et al. Relation of serum lipoprotein levels and systolic blood pressure to early atherosclerosis. The Bogalusa heart study. N Engl J Med. 1986;314(3): 138-44. https://doi.org/10.1056/NEJM198601163140302.

95. Rademacher ER, Jacobs DR Jr, Moran A, Steinberger J, Prineas RJ, Sinaiko A. Relation of blood pressure and body mass index during childhood to cardiovascular risk factor levels in young adults. J Hypertens. 2009;27(9): 1766-74. https://doi.org/10.1097/HJH.0b013e32832e8cfa.

96. Sorof JM, Alexandrov AV, Garami Z, Turner JL, Grafe RE, Lai DJ, et al. Carotid ultrasonography for detection of vascular abnormalities in hypertensive children. Pediatr Nephrol. 2003;18(10):1020-4. https://doi.org/10.1007/s004 67-003-1187-0.

97. Doyon A, Kracht D, Bayazit AK, Deveci M, Duzova A, Krmar RT, et al. Carotid artery intima-media thickness and Distensibility in children and adolescents: reference values and role of body dimensions. Hypertension. 2013;62(3): 550-6. https://doi.org/10.1161/HYPERTENSIONAHA.113.01297.

98. Litwin M, Trelewicz J, Wawer Z, Antoniewicz J, Wierzbicka A, Rajszys P, et al. Intima-media thickness and arterial elasticity in hypertensive children: controlled study. Pediatr Nephrol. 2004;19(7):767-74. https://doi.org/10.1 007/s00467-004-1480-6.

99. Pauciullo P, lannuzzi A, Sartorio R, Irace C, Covetti G, Di Costanzo A, et al. Increased intima-media thickness of the common carotid artery in hypercholesterolemic children. Arterioscler Thromb. 1994;14(7):1075-9. https://doi.org/10.1161/01.ATV.14.7.1075

100. Kallio K, Jokinen E, Saarinen M, Hamalainen M, Volanen I, Kaitosaari T, et al. Arterial intima-media thickness, endothelial function, and apolipoproteins in adolescents frequently exposed to tobacco smoke. Circ Cardiovasc Qual Outcomes. 2010;3(2):196-203. https://doi.org/10.1161/CIRCOUTCOMES.109. 857771.

101. Asghari G, Dehghan P, Mirmiran P, Yuzbashian E, Mahdavi M, Tohidi M, et al. Insulin metabolism markers are predictors of subclinical atherosclerosis among overweight and obese children and adolescents. BMC Pediatr. 2018; 18(1):368. https://doi.org/10.1186/s12887-018-1347-9.

\section{Publisher's Note}

Springer Nature remains neutral with regard to jurisdictional claims in published maps and institutional affiliations.
Ready to submit your research? Choose BMC and benefit from:

- fast, convenient online submission

- thorough peer review by experienced researchers in your field

- rapid publication on acceptance

- support for research data, including large and complex data types

- gold Open Access which fosters wider collaboration and increased citations

- maximum visibility for your research: over $100 \mathrm{M}$ website views per year

At BMC, research is always in progress.

Learn more biomedcentral.com/submissions 